\title{
Consideration of fatigue resistance tests variability in pavement design methodology
}

\author{
Josef Žák ${ }^{\mathrm{a} *}$, Carl L. Monismith ${ }^{\mathrm{b} 1}$ and Daniela Jaruškovác2 \\ ${ }^{a}$ Faculty of Civil Engineering, Department of Road Structures, CTU in Prague, Thakurova 7, Prague 166 29, Czech Republic; ${ }^{b}$ Faculty of \\ Civil and Environmental Engineering, University of California, Berkeley, 760 Davis Hall, Berkeley, CA, USA; ${ }^{c}$ Faculty of Civil \\ Engineering, Department of Mathematics, CTU in Prague, Thakurova 7, Prague 166 29, Czech Republic
}

(Received 3 June 2014; accepted 5 July 2014)

\begin{abstract}
The article is focused on the description of a road pavement design procedure and introduces a specific method of considering the repeatability and reproducibility of the fatigue resistance test. An example is taken from the Czech Road Pavement Design Methodology pursuant to TP 170 (2004, Navrhování Vozovek Pozemních Komunikací, Ministry of Transport, Czech Republic, available from: http://www.pjpk.cz/TP\%20170.pdf). The article draws on foreign experience in the consideration of fatigue resistance in France and the USA, and the objective of the designed methodology is to bring the results of laboratory tests closer to a specific road pavement design allowing a better distinction in the quality of bitumen mixtures used in the design of road pavements.
\end{abstract}

Keywords: fatigue resistance; pavement design; repeatability; reproducibility; partial variance coefficient

\section{Introduction}

The maximum tensile stress in the road pavement mostly arises on the lower face of the bottom layer bound by bitumen; therefore, it provokes the appearance of a fatigue crack due to repetitive loading and its development proceeding from the bottom upwards (Rao Tangela et al. 1990). Despite this, numerous road pavement structures manifest cracks which have nothing in common with tensile stresses on the lower face of bound road pavement layers arising on the surface and propagating in the downward direction (Molenaar 2007).

Regardless of the direction of a crack developing in a road pavement structure, individual layers or the quality of materials used in individual layers in terms of fatigue resistance, are assessed by a laboratory test of fatigue resistance. As it is a key characteristic entering the design methodologies of bitumen road pavements in countries across the continents, discussions on individual methods, their exact description, the applicability and usability of these tests or on their alternative versions are continuously running in the professional community.

Design methodologies are generally based on multilayer elastic systems which assess the susceptibility of a bitumen mixture at a critical point of a road pavement to the appearance of fatigue cracks for presumed in situ conditions. To ensure that the stress and strain in the active zone, or the subsoil of the road pavement structure, do not cause rutting, vertical strain on the subgrade is limited in the design.

Design methodologies are subsequently calibrated in relation to the behaviour of road pavement structures (test sections) to best fit the real service life of a road pavement structure in in situ conditions (Monismith et al. 2000, 2009).

A traditional common engineering approach is the design of a road pavement with a high thickness using bituminous layers with a high Young's modulus for higher classes of roads with high traffic volumes. Thus, due to the multi-layer theory of the road pavement design and the height-to-stiffness ratio, the strain at the lower face of consolidated layers is reduced to such a level where higher fatigue resistance is ensured. On the other hand, road pavements with lower traffic volumes should rather be of a flexible type (with a lower thickness of bound layers) using open-graded asphalt mixes with a lower Young's modulus, but high resistance to repetitive loading (Freeme and Marais 1973, Monismith et al. 2009).

The state of the art and the design methodology of the road pavement design described in more detail in TP 170 (2004) allow considering such a design approach. In practice, however, it is not applied, in particular for the reason of the absence of a library of material properties for specific local resources in the programmes used for road pavement design.

In other words, an engineer may hardly apply such procedures if the tool used for the design does not allow the variability of certified inputs and, therefore, does not provide relevant results that will clearly distinguish the service life of a road pavement structure. It is, therefore, necessary to apply the feeling for material properties and their use in the designs of pavement structures for less significant roads as well. 
The alternative can be the consideration of crack appearance and the assessment of permanent deformations in the pavement structure rather than its elastic strain applying the theory of viscoelasticity. The procedure may easily be imagined: the total strain (elastic + permanent) is added up to check for the subsoil effect; however, the parameter of a greater informative value for the road pavement structure itself is the accumulated permanent deformation of the pavement structure in individual layers with the combination of resistance to crack formation.

Because of the calibration of design methods, this effect is basically indirectly accounted for in the current design methodology. However, some types of newly applied materials (e.g. modified asphalt binders, foamed bitumen and cold recycling) may be underrated by using the current approach. Thus, this approach may prevent the consideration of the advantages of newly developed materials in the design methodology and, in its consequences, prevent their application in road construction, although these materials might otherwise contribute to the quality enhancement of the road network and save taxpayers' money.

\section{Consideration of the fatigue resistance test in existing design methodology}

The proposed amendment is based on experience in accelerated testing of road pavement structures, on the results measured on test sections and their calibration against the design methodology, Mechanistic Empirical Pavement Design, in the USA, which also considers the variability of the fatigue resistance test (Tsai et al. 2012). The article is further based on already published conclusions from the inter-laboratory comparison of the repeatability and reproducibility of the fatigue resistance test performed in France and circular tests (De La Roche 2001), and the results of the inter-laboratory comparison of indirect tensile fatigue tests (ITFTs; Said et al. 2012).

The suggested procedure is further illustrated by the ACO $11+$ compacted bitumen mixture designed according to ČSN EN 13108-1 (2008) with the 5.2\% contents of virgin binder $50 / 70$ and $3.5 \%$ of air void content. The measured fatigue resistance data are presented in Table 1 and further used to demonstrate the effect of described approach. Concentrating on the probabilistic analysis of the formula for the expression of the lower limit of the
95\% confidence interval for linear regression with one explanatory variable, the dependence of measured data in logarithm is expressed by a straight line taking the form:

$$
y=A+B \times x,
$$

where $A$ and $B$ are the estimated line coefficient values. It further holds true for the lower limit of the one-sided prediction interval that (Jaruskova 2006)

$$
y^{\min }=\bar{A}+\bar{B} \times x-t_{\mathrm{p}} \times s_{y / x} \sqrt{1+\frac{1}{n}+\frac{(x-\bar{x})^{2}}{\sum\left(x_{i}-\bar{x}\right)^{2}}},
$$

where $\bar{A}$ and $\bar{B}$ are linear regression estimators, $n$ is the number of measurements, $\bar{x}$ is the sample mean of $x, s_{y / x}$ is the residual standard deviation in linear regression and $t_{\mathrm{p}}$ is the $5 \%$ upper quantile of $(n-2)$ degrees of freedom. When $n \geq 20$, the $t_{\mathrm{p}} \approx 1.65$.

If we further want to specify the partial variance coefficient of the fatigue line $\gamma_{\text {úp }}$ (TP 170 2004) for the purposes of its use in the road pavement design methodology, we may basically depart from two formulae.

\section{The number of cycles as an independent variable}

If we use formula (3) for Wöhler (or the so-called $S-N$ ) curves for the expression of the fatigue resistance test in TP 170 (2004, paragraph B.7.8.4) instead of formula (1):

$$
\log (\varepsilon)=A+B \times \log (N),
$$

where $\varepsilon$ is the strain and $N$ the number of cycles identified by the fatigue resistance test, then, the lower limit of the 95\% prediction interval for 1 million cycles after the substitution in formula (2) is expressed by the equation:

$$
\begin{aligned}
\varepsilon_{6.5 \%}= & 10 \exp \left[\log \left(\varepsilon_{6,50 \%}\right)-t_{\mathrm{p}}\right. \\
& \times s_{\log (\varepsilon / N)} \sqrt{1+\frac{1}{n}+\frac{(6-\overline{\log (N)})^{2}}{\sum\left(\log \left(N_{i}\right)-\overline{\log (N)}\right)^{2}}} .
\end{aligned}
$$

The $\varepsilon_{6.5 \%}$ value is the minimum magnitude of strain derived from the fatigue line at $10^{6}$ cycles for the $5 \%$ probability of occurrence.

A common parameter used in the literature for the description of repeatability and reproducibility is the

Table 1. Used example of measured data from 4PB-PR test.

\begin{tabular}{lccccccc}
\hline Number of cycles & {$[-]$} & $2,371,691$ & $1,020,697$ & 783,979 & $1,141,262$ & 796,468 & $1,254,670$ \\
Strain & {$[\mu$ strain] } & 150 & 150 & 150 & 150 & 150 & 150 \\
Number of cycles & {$[-]$} & 525,827 & 410,719 & 810,536 & 432,288 & 272,616 & 354,699 \\
Strain & {$[\mu$ strain] } & 180 & 180 & 180 & 180 & 180 & 180 \\
Number of cycles & {$[-]$} & 215,091 & 139,013 & 173,049 & 149,066 & 113,019 & 184,038 \\
Strain & {$[\mu$ strain] } & 210 & 210 & 210 & 210 & 210 & 210 \\
\hline
\end{tabular}


Table 2. Repeatability and reproducibility of individual test methods of fatigue resistance.

\begin{tabular}{|c|c|c|c|c|c|}
\hline \multirow{2}{*}{$\begin{array}{l}\text { Test method } \\
\text { Source }\end{array}$} & \multirow{2}{*}{$\frac{\text { 2PBB-TR }}{\text { De La Roche (2001) }}$} & \multirow{2}{*}{\multicolumn{2}{|c|}{$\frac{\text { ITFT }}{\text { Said et al. (2012) }}$}} & \multicolumn{2}{|c|}{ 4PBB-PR } \\
\hline & & & & $\begin{array}{l}\text { ASTM designation } \\
\text { D7460-10 (2010) }\end{array}$ & Prowell et al. (2010) \\
\hline Value expressed as & Standard deviation $[-]$ & \multicolumn{2}{|c|}{$\begin{array}{l}\text { Standard devi- } \\
\text { ation in log [-] }\end{array}$} & \multicolumn{2}{|c|}{ Standard deviation in $\log [-]$} \\
\hline Repeatability & 1.430 & 0.196 & 0.238 & 0.278 & 0.248 \\
\hline Reproducibility & 2.930 & 0.247 & 0.389 & $-*$ & $0.318^{* *}$ \\
\hline Number of inter-laboratory tests & 11 & 7 & 6 & $-*$ & $5 * *$ \\
\hline
\end{tabular}

standard deviation. The summary of the results of projects dealing with the repeatability and reproducibility of fatigue resistance tests is presented in Table 2. If we want to calculate the specific value of the partial variance coefficient of the fatigue test, $\gamma_{\text {úp }}$, reproducibility must be added to this lower limit. This means that the variability of the value measured repeatedly in one laboratory and the variability of values measured in more laboratories must be included. Reproducibility may be considered based on the values of the standard deviation in log presented in Table 2 using the formula: road pavement design, the coefficient $\gamma_{\text {úp }}$ must be placed in front of the brackets and the formula for the calculation of the ultimate number of repetitive loading must be modified; an example may be the formula used in paragraph B.10.2.3 of TP 170. To follow the logic using formula (6) for the expression of the regression of measured data, the formula should take the form:

$$
N_{i j, \lim }=\frac{10^{6}}{\gamma_{\mathrm{d}} \times C_{2} \times C_{4} \times \gamma_{\text {úp }}}\left(\frac{\gamma_{\mathrm{u}} \gamma_{\mathrm{D}} \varepsilon_{6}}{\varepsilon_{i j}}\right)^{\mathrm{B}}
$$

$$
\varepsilon_{6.5 \%}=10 \exp \left[\log \left(\varepsilon_{6.50 \%}\right)-t_{\mathrm{p}} \sqrt{\left(s_{\log (\varepsilon / N)^{2}}+S_{m^{2}}\right) \times\left[1+\frac{1}{m \times n}+\frac{(6-\overline{\log (N)})^{2}}{m \times \sum\left(\log \left(N_{i}\right)-\overline{\log (N)}\right)^{2}}\right]}\right]
$$

where $S_{m}$ is the standard deviation in $\log$ and $m$ is the number of inter-laboratory tests from Table 2 .

It is necessary to mention two notes to the values reported in the Table 2. Ad*) According to ASTM D746010, the reproducibility should be reported till June 2013. However, according to the available information, the values have not been determined yet. The value of repeatability was taken from ASTM D7460-10 to present the similarity with the value given in NCHRP Report 646. Ad **) The reproducibility values reported in NCHRP Report 646 were determined by comparing the results of only five laboratories (mini round robin test) and the standard deviation is calculated for the number of cycles. The standard deviation is approximate because the aim of NCHRP 646 project was among other things to evaluate the endurance limit.

The partial variance coefficient of the fatigue test is subsequently calculated as

$$
\gamma_{\text {úp }}=\frac{\varepsilon_{6.50 \%}}{\varepsilon_{6.5 \%}} .
$$

The formula for the coefficient $\gamma_{\text {úp }}$ remains unchanged. The procedure described above is only specification of the calculation which is not specified in more detail in TP 170 . The pavement design formulation is completed by reproducibility to include the between-laboratory variance. In order to further follow the logic of the formula for
For the reference asphalt mixture, the value of the coefficient $\gamma_{\text {úp }}$ equals 3.4. Restating this value to original equation listed in B.10.2.3 TP 170, the $\gamma_{\text {úp }}$ would equal 1.28. Without the introduction of reproducibility into formula (5), the calculated value of the coefficient $\gamma_{\text {úp }}$ would be equal to 1.13 . Thus, the use of the value specified in this way would undersize the road pavement design.

Considering the value of 1.15 , which is recommended for this type of mixture in TP 170, it is evident that the value specified in TP 170 is smaller than the one actually calculated. By increasing this value, the road pavement design considering the material resistance to fatigue approaches the values used in the USA and France. The value of the coefficient $\gamma_{\text {úp }}$ equalling 1.28 is closer to the value of 1.25 which should be used for a mixture with the grading over $16 \mathrm{~mm}$ and the void fraction over $10 \%$. The concept of described design values is presented in Figure 1.

\section{Strain as an independent variable}

The second alternative is the utilisation of the formula for resistance to fatigue from ČSN EN 12697-24 + A1 (2007), which is based on the formula:

$$
\log (N)=a+b \times \log (\varepsilon)
$$




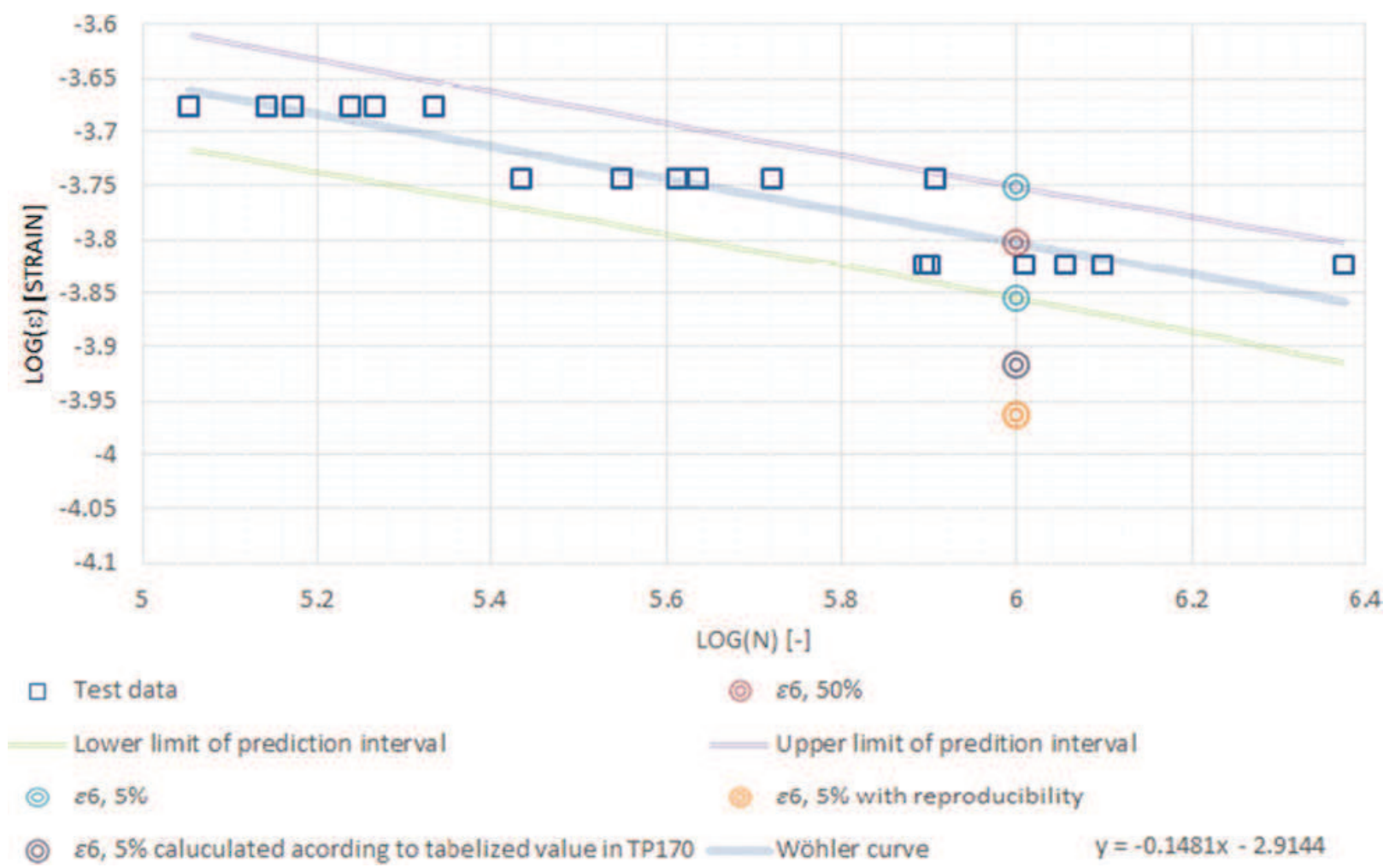

Figure 1. Comparison of calculated points characteristic for material resistance to fatigue.

If formula (2) is used to express the $95 \%$ prediction interval for 1 million cycles, the $95 \%$ prediction interval is calculated for cycles. The number of cycles with a $95 \%$ prediction interval, including reproducibility, may be calculated from the formula: the subsequently adopted (ČSN EN 12697-24 + A1 2007) standard.

The specific value of the coefficient $\gamma_{\text {úp }}$ for the reference mixture calculated from formula (10) is 3.81 . This value basically corresponds to the use of the

$$
N_{6.5 \%}=10 \exp \left[6-t_{\mathrm{p}} \sqrt{\left(s_{\log (N / \varepsilon)^{2}}+S_{m^{2}}\right) \times\left[1+\frac{1}{m \times n}+\frac{\left(\varepsilon_{6.50 \%}-\overline{\log (\varepsilon)}\right)^{2}}{m \times \sum\left(\log \left(\varepsilon_{i}\right)-\overline{\log (\varepsilon)}\right)^{2}}\right]}\right] .
$$

The calculation of the partial variance coefficient of the fatigue test may proceed as follows:

$$
\gamma_{\text {úp }}=\frac{10^{6}}{N_{6.5 \%}}
$$

In this way, we have identified the coefficient regulating the number of calculated cycles (repetitive loading), including the variability of the fatigue resistance test and reproducibility. To account this coefficient, we may use Equation (7).

The above-presented approach implements formula (8) used in ČSN EN 12697-24 + A1 (2007) to express resistance to fatigue. Thus, it integrates the procedure introduced into TP 77 and further adopted in TP 170 with coefficient $\gamma_{\text {úp }}$ equalling 1.31 calculated from formula (6). Thus, the proposed approach makes possible to calculate the coefficient $\gamma_{\text {úp }}$ from measured data in laboratory, implements the differences between Equation (3) in Czech pavement design methodology (TP 170) and Equation (8) in European standardisation CSN EN 12697-24 + A1 and brings the calculated coefficient near to values used in the USA and France.

\section{Conclusion}

The article describes two procedures considering the variability and repeatability of the fatigue resistance test. The first is a follow-up to the existing procedure listed in TP 170, based on previous TP 77, while the latter takes 
into account the adoption of the ČSN EN 12697-24 + A1 (2007) standard, from 2005, allowing the performance of the fatigue resistance test according to EN and implementing simultaneously the result into the design methodology according to TP 170 .

Following a wider discussion, it is up to the professional community to decide which of the above formulae should be incorporated into the TP 170 amendment.

One of the objectives of a design methodology should be the support of construction of road pavement structures possessing a significantly better service life as compared to those complying only with the minimum standard regulations keeping, at the same time, the price at a reasonable level. The fact that the manufacturer of bitumen mixes does not design the optimum mixture in terms of the total service life, but just a mixture complying with the minimum standard regulations, should be considered in the design methodology. Such a methodology should allow the consideration of specific characteristics of bitumen mixtures, and support new technologies and high-quality materials resulting eventually in financial economies reached in the road construction and maintenance cycle. These objectives may be achieved by including specific values measured by an accredited laboratory in the design of road pavement structures.

The above proposed specification of the TP 170 methodology may be one of little steps bringing laboratory measured data closer to the design of road pavement structures. In particular, the coefficient $\gamma_{\text {úp }}$ and the $\varepsilon_{6.5 \%}$ values for individual materials should be introduced in the test protocol. Furthermore, this value should be directly used in the pavement design. Based on these parameters, designers may take into account specific material characteristics in the design thus selecting a better combination for specific use from local resources.

It must be noted that the presented results refer to the measurement of resistance to fatigue applying the four point bending beam on prismatic beam (4PBB-PB) method. According to the latest knowledge, the variability of the measurement applying the ITFT is lower, while applying the two point bending on trapezoidal beam (2PBTB) test, it is greater than that of the 4PBB-PB method considered in the article (SHRP-A-404 1994). This fact is supported by the results of current research summarised in Table 2. The fatigue resistance method based on the ITFT is presently the subject of considerable criticism. The topics for the criticism are the biaxial stress pattern, the underrating of resistance to fatigue, the impossibility of performing the test in the controlled strain mode, the accumulation of permanent deformation during the test and the failure of a specimen which is not due to indirect tensile fatigue (Hudson and Kennedy 1968, SHRP-A-404
1994, Benedetto et al. 2004). Hence, its adoption in the design methodology according to TP 170 should either specify individual values of repeatability for the 4PBB-PB and $2 \mathrm{PBB}-\mathrm{TB}$ methods or choose one of them that will be used for the identification of resistance to repetitive loading.

\section{Funding}

This work was supported by the Faculty of Civil Engineering, Czech Technical University in Prague [grant number SGS13/ 050/OHK1/1T/11T].

\section{Notes \\ 1. Email: clm@ce.berkeley.edu \\ 2. Email: jarus@mat.fsv.cvut.cz}

\section{References}

ASTM Designation D7460-10, 2010. Test method for determining fatigue failure of compacted asphalt concrete subjected to repeated flexural bending. West Conshohocken, PA: ASTM International. doi:10.1520/D7460-10. www.astm.org

Benedetto, H., et al., 2004. Fatigue of bituminous mixtures. Materials and Structures, 37 (3), 202-216, doi:10.1007/ BF02481620

C SN EN 12697-24 + A1, 2007. Bituminous mixtures - test methods for hot mix asphalt - part 24: resistance to fatigue. Prague, Czech Republic: Czech Office for Standards, Metrology and Testing.

ČSN EN 13108-1, 2008. Bituminous mixtures - material specification - part 1: asphat concrete. Prague, Czech Republic: Czech Office for Standards, Metrology and Testing.

De La Roche, C., 2001. Essai de Fatigue Sur Lex Enrobés Bitumineux. Résultats de L'expérience D'exactitude. Revue Generale Des Routes (RGRA), 793, 30-33.

Freeme, C.R. and Marais, C.P., 1973. Thin bituminous surfaces: their fatigue behavior and prediction. Washington, DC: Transportation Research Board Business Office, ISSN 03353191.

Hudson, W.R. and Kennedy, T.W., 1968. An indirect tensile test for stabilized materials. Research Report 9801. Austin, TX: Center for Highway Research, The University of Texas.

Jaruskova, D., 2006. Probability and mathematical statistics. Prague, Czech Republic: Česká technika - Publishing House ČVUT, ISBN 80-01-03427-5.

Molenaar, A., 2007. Prediction of fatigue cracking in asphalt pavements: do we follow the right approach? Transportation Research Record: Journal of the Transportation Research Board, 2001 (1), 155-162, doi:10.3141/2001-17

Monismith, C.L., Deacon, J.A., and Harvey, J., 2000. WesTrack: performance models for permanent deformation and fatigue. Berkeley, CA: Pavement Research Center; Institute of Transportation Studies, University of California.

Monismith, C.L., et al., 2009. Summary report: the phase 1 I-710 freeway rehabilitation project: initial design (1999) to performance after five years of traffic (2009). Davis and Berkeley: University of California.

Prowell, B.D., et al., 2010. NCHRP report 646: validating the fatigue endurance limit for hot mix asphalt. Washington, DC: 
Transportation Research Board - National Research Council, ISBN 97-0-309-11821-7.

Rao Tangela, S.C.S., et al., 1990. Summary Report on Fatigue Response of Asphalt Mixtures. Washington, DC: Strategic Highway Research Program, National Research Council.

Said, S.F., et al., 2012. Interlaboratory experiment of asphalt concrete using indirect tensile fatigue test. In: 5th Euroasphalt and Eurobitume Congress - 2012. Istanbul: EAPA-European Asphlat Pavement Association, ISBN 97890-802884-0-9 1-9.
SHRP-A-404, 1994. Fatigue Response of Asphalt-Aggregate Mixes. Washington, DC: Strategic Highway Research Program, National Research Council, ISBN 0-309-05812-0.

TP 170, 2004. Navrhování Vozovek Pozemních Komunikací. Ministry of Transport, Czech Republic. Available from: http://www.pjpk.cz/TP\%20170.pdf

Tsai, B.W., et al., 2012. Development of fatigue performance specification and its relation to mechanistic-empirical pavement design using four-point bending beams test results. In: Proceedings of $3 r d$ conference on four-point bending. Davis, CA: CRC Press, 59-71. 